\title{
Effect of stacking fault energy on mechanical properties and annealing behavior of brasses
}

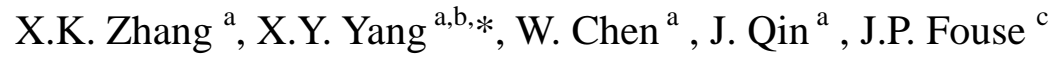 \\ ${ }^{a}$ Educational Key Laboratory of Nonferrous Metal Materials Science and Engineering, \\ School of Materials Science and Engineering, Central South University, Changsha, \\ 410083, China \\ ${ }^{\mathrm{b}}$ Institute for Materials Microstructure, Central South University, Changsha,410083, \\ China \\ ${ }^{\mathrm{c}}$ State of Hawaii, Department of Health/Environmental division, Clean Water Branch, \\ USA \\ Corresponding author. Tel: +86-731-88876470, fax: +86-731-88830136 \\ E-mail address: yangxycsu@ 163.com
}

\begin{abstract}
The effect of stacking fault energy (SFE) on mechanical properties and annealing behavior of brasses was studied in $\mathrm{Cu}-20 \mathrm{Zn}$ alloy (SFE $\sim 18 \mathrm{~mJ} / \mathrm{m}^{2}$ ) and $\mathrm{Cu}-20 \mathrm{Zn}-1.2 \mathrm{Si}$ alloy $\left(\mathrm{SFE} \sim 9 \mathrm{~mJ} / \mathrm{m}^{2}\right.$ ) as well as $\mathrm{Cu}-20 \mathrm{Zn}-1.9 \mathrm{Si}$ alloy (SFE $\sim 6$ $\mathrm{mJ} / \mathrm{m}^{2}$ ) alloy. These brasses have been rolled at room temperature up to different thickness reductions. The significant improvement of strength in $\mathrm{Cu}-20 \mathrm{Zn}-1.9 \mathrm{Si}$ alloy is attributed to the formation of fine grains and high densities of dislocations and deformation twins by decreasing the SFE. Thermal stability is enhanced due to the reductions of dislocation mobility and grain boundaries migration during annealing by a decrease in SFE and addition of Si. High fractions of the $\{236\}\langle 385\rangle$ Brass-R and $(55 ; 30 ; 0)$ in $\mathrm{Cu}-20 \mathrm{Zn}-1.9 \mathrm{Si}$ alloy with lower SFE should be ascribed to the
\end{abstract}


substantial Brass texture in deformed microstructures. Fine grains, deformation twins and abundant annealing twins were introduced into $\mathrm{Cu}-20 \mathrm{Zn}-1.9 \mathrm{Si}$ alloy by decreasing the SFE, resulting in superior strength-ductility combination.

Keywords: copper alloy; rolling; mechanical properties; twins; annealing.

\section{Introduction}

It has been widely acknowledged that the dislocation slip and twinning are two competitive plastic deformation mechanisms in face-centered cubic (fcc) metals $[1,2]$. Stacking fault energy (SFE) is an important parameter which has closely related to the deformation mechanisms. To date, most researches have concentrated on in metals with relatively high values for SFE so that dislocation slip would be the dominant deformation mechanism in plastic deformation [3-5]. With decreasing the SFE, the deformation mechanism will transfer from dislocation slip to twinning, and the grain refinement mechanism in plastic deformation will also change [6]. In metals with the high or medium SFE, the substantial dynamic recovery occurs by balancing multiplication and annihilation of dislocations, more interactions between dislocations and grain boundaries are in favor of the annihilation processes. Accordingly, no more dislocation boundaries can be formed, impeding the further subdivision of grains [7]. Twinning, a prevalent deformation mechanism in low SFE metals, plays a significant role in grain refinement. It primarily stems from the interactions between dislocations and twin boundaries resulting in the fragmentation of twin bundles. Meanwhile, the role of shear bands in refining the original coarse grains is also crucial. Therefore, it is reasonable to expect that the grain size can be refined down to the nanoscale for metals with low or extremely low SFE even under relatively gentle deformation conditions $[8,9]$.

Previous study [7] indicated that the strength and uniform elongation were simultaneously improved by decreasing the SFE in $\mathrm{Cu}-\mathrm{Al}$ alloys. This simultaneity was attributed to the formation of profuse deformation twins and shear bands, and their extensive intersections. Although the overall mechanical properties were 
improved with decreasing the SFE, the uniform elongation was still limited. Therefore, in recent years much attention has been paid to developing strategies for improving the limited ductility [10-14]. Thermal annealing has been found to be effective on improving the ductility. It was found that SFE plays crucial role in thermal annealing [15-17].

Therefore, in this work, regarding the significance of SFE in plastic deformation and thermal annealing, the effect of SFE on the mechanical properties and annealing behavior of $\mathrm{Cu}-\mathrm{Zn}$ and $\mathrm{Cu}-\mathrm{Zn}-\mathrm{Si}$ alloys was investigated. Meanwhile, the effect of SFE on the recrystallization texture and strength-ductility combination of these alloys during annealing was also studied.

\section{Materials and Methods}

$\mathrm{Cu}-20 \% \mathrm{Zn}, \mathrm{Cu}-20 \% \mathrm{Zn}-1.2 \% \mathrm{Si}$ and $\mathrm{Cu}-20 \% \mathrm{Zn}-1.9 \% \mathrm{Si}$ alloys (all compositions are in weight percent) were prepared by induction vacuum melting. The addition of $\mathrm{Si}$, the valance of which is four, leads to a significant decrease in SFE [18]. The ternary alloy is especially designed to obtain minimum SFE in copper rich alloys. SFEs of the ternary alloys were calculated using the following equation and available data on the SFEs of binary alloys $[19,20]$ :

$$
\frac{\gamma-\gamma_{\mathrm{Cu}-\mathrm{Zn}}}{\gamma_{\mathrm{Cu}-\mathrm{Si}}-\gamma_{\mathrm{Cu}-\mathrm{Zn}}}=\frac{C_{a}-(\mathrm{Al})_{E}}{(\mathrm{Zn})_{E}-(\mathrm{Al})_{E}}=\frac{2 C_{a}}{e / a-1}-1
$$

where $\gamma_{\mathrm{Cu}-\mathrm{Zn}}$ and $\gamma_{\mathrm{Cu}-\mathrm{Si}}$ are SFEs for binary alloys with the same electron/atom ratio (e/a) as the ternary solid solution and with the respective atomic fraction contents $(\mathrm{Al})_{E}$ and $(\mathrm{Zn})_{E} \cdot C_{a}$ is the total atomic fraction of solute content. SFEs of $\mathrm{Cu}-20 \mathrm{Zn}$, $\mathrm{Cu}-20 \mathrm{Zn}-1.2 \mathrm{Si}$ and $\mathrm{Cu}-20 \mathrm{Zn}-1.9 \mathrm{Si}$ alloys are $18 \mathrm{~mJ} / \mathrm{m}^{2}, 9 \mathrm{~mJ} / \mathrm{m}^{2}$ and $6 \mathrm{~mJ} / \mathrm{m}^{2}$, respectively.

In order to homogenize the composition, the casting ingots with thickness of 15 $\mathrm{mm}$ were heated at $830{ }^{\circ} \mathrm{C}$ for $1 \mathrm{~h}$ and then hot-rolled to thickness of $5.5 \mathrm{~mm}$. The plates were finally annealed at $490{ }^{\circ} \mathrm{C}$ for $50 \mathrm{~min}$ and then quenched in water. These alloys were then rolled at room temperature up to different thickness reductions. The 
X-ray diffraction (XRD) measurements were carried out on a Rigaku X-ray diffractometer equipped with a $\mathrm{Cu}$ target. The Vickers hardness was measured at room temperature under a load of $1000 \mathrm{~g}$ and for a duration time of $30 \mathrm{~s}$. Measurements at least 9 different points for each sample were taken to obtain an average hardness. Tensile specimens have gauge lengths of $6 \mathrm{~mm}$ and widths of $1 \mathrm{~mm}$. Tensile tests were conducted at an initial strain rate of $3 \times 10^{-3} \mathrm{~s}^{-1}$ at room temperature. Electron backscatter diffraction (EBSD) observations were made in the longitudinal plane containing the rolling direction (RD) and normal direction (ND), the rolling plane containing the RD and transverse direction (TD), and the cross plane containing the TD and ND. To make reliable measurements, all low angle grain boundaries with a misorientation less than $2^{\circ}$ were excluded. The misorientation of $15^{\circ}$ was used as the criterion to distinguish the low angle grain boundaries (LAGBs) and high angle grain boundaries (HAGBs). Microstructures in the rolling plane and longitudinal plane were also determined using the transmission electron microscope (TEM) technique. Thin foils were prepared by utilizing a conventional jet polishing technique in a solution of $25 \% \mathrm{HNO}_{3}$ and $75 \%$ Methanol.

\section{Results and Discussion}

\subsection{Deformed microstructures and tensile properties of brasses}

The three-dimensional EBSD microstructures of the $\mathrm{Cu}-20 \mathrm{Zn}$ and $\mathrm{Cu}-20 \mathrm{Zn}-1.9 \mathrm{Si}$ alloys after a thickness reduction of $30 \%$ are shown in Fig. 1. $\mathrm{Cu}-20 \mathrm{Zn}$ alloy exhibits relatively coarse grains compared to $\mathrm{Cu}-20 \mathrm{Zn}-1.9 \mathrm{Si}$ alloy in all three planes. $\mathrm{Cu}-20 \mathrm{Zn}$ alloy shows deformed grains, which are elongated along the RD and TD in the longitudinal plane and cross plane, respectively. However, the severely fragmented and elongated grains were observed in $\mathrm{Cu}-20 \mathrm{Zn}-1.9 \mathrm{Si}$ alloy. As compared to $\mathrm{Cu}-20 \mathrm{Zn}$ alloy, the length of the elongated grain size is less in $\mathrm{Cu}-20 \mathrm{Zn}-1.9 \mathrm{Si}$ alloy.

Fig. 2 shows the micrographs of $\mathrm{Cu}-20 \mathrm{Zn}$ and $\mathrm{Cu}-20 \mathrm{Zn}-1.9 \mathrm{Si}$ alloys after a thickness reduction of $90 \%$. A heavily deformed microstructure and dislocation cells 
were observed in $\mathrm{Cu}-20 \mathrm{Zn}$ alloy, as shown in Fig. 2a. The microstructures of $\mathrm{Cu}-20 \mathrm{Zn}$ alloy exhibit lamellar grains lying parallel to RD in Fig. b. As compared to $\mathrm{Cu}-20 \mathrm{Zn}$ alloy, a severely deformed microstructure with ill-defined grain boundaries and much higher dislocations density as well as lamellar grains were observed in $\mathrm{Cu}-20 \mathrm{Zn}-1.9 \mathrm{Si}$ alloy. Moreover, deformation twins (marked by circles in Fig. 2b, d) inclined to the RD by an angle of $45^{\circ}$ were observed in $\mathrm{Cu}-20 \mathrm{Zn}-1.9 \mathrm{Si}$ alloy.

The dislocation density, twin density and grain size of the $\mathrm{Cu}-20 \mathrm{Zn}$, $\mathrm{Cu}-20 \mathrm{Zn}-1.2 \mathrm{Si}$ and $\mathrm{Cu}-20 \mathrm{Zn}-1.9 \mathrm{Si}$ alloys were measured by using XRD analysis The dislocation density $\rho$ can be calculated based on microstrain, using the following equation [19]:

$$
\rho=16.1 \times \varepsilon^{2} / b^{2}
$$

where $\varepsilon$ is the microstrain, $b$ is the Burgers vector and $b=(\sqrt{2} / 2) \mathrm{a}$, and $a$ is the lattice constant in fcc metals. The twin density $\beta$, defined as the probability of finding a twin boundary between any two neighboring $\{111\}$ planes, may be calculated based on the equation $[21,22]$ :

$$
\beta=\frac{\Delta C . G .(2 \theta)_{111}-\Delta C . G .(2 \theta)_{200}}{11 \tan \theta_{111}+14 \cdot 6 \tan \theta_{200}}
$$

where $\Delta C . G .(2 \theta)_{111}$ and $\Delta C . G .(2 \theta)_{111}$ are the angular deviations of the gravity center from the peak maximum of the $\{111\}$ and $\{200\}$ XRD peaks, respectively. The grain size can be calculated by the Williamson-Hall method [23]. It is known that XRD analysis often yields a smaller grain size because it measures the sizes of coherent-diffraction domains [24]. The calculated results of these three main factors are shown in Table 1. An increase in the dislocation density and twin density from $1.6 \times 10^{15} \mathrm{~m}^{-2}, 0.05 \%$ to $6.1 \times 10^{15} \mathrm{~m}^{-2}, 0.26 \%$ when the SFE decreases from 18 to 6 $\mathrm{mJ} / \mathrm{m}^{2}$ for $\mathrm{Cu}-20 \mathrm{Zn}$ alloy and $\mathrm{Cu}-20 \mathrm{Zn}-1.9 \mathrm{Si}$ alloy, respectively. The grain size decreases from 103 to $42 \mathrm{~nm}$ with decreasing SFE from 18 to $6 \mathrm{~mJ} / \mathrm{m}^{2}$.

It is well known that SFE has close relationship with the deformation mechanisms [25]. On one hand, a decrease in SFE facilitates the full dislocations to split into two partials with a wide stacking fault between them, the lower the SFE, the wider the 
stacking fault [26]. The stacking fault can acts as a barrier for full dislocations to cross slip or climb, which suppresses the dislocation recovery via cross slip and climb [23]. On the other hand, with decreasing SFE, the stress necessary for dislocation slip is greater than that for twinning, and deformation twins would easily form with decreasing SFE [1]. Moreover, deformation twins caused by lowering SFE may serve as locations for dislocation accumulation [27]. Consequently, a lower SFE usually leads to a higher dislocation density and twin density. As proved by the results of TEM and XRD.

SFE determines not only the deformation mechanisms but also the grain refinement mechanisms. For metals with medium to high SFE, dislocation subdivision is the dominant grain refinement mechanism due to the extensive dislocation movement. With a decrease in SFE, deformation twins would be prevalent in plastic deformation $[28,29]$. The grain refinement mechanism gradually transfers from the dislocation subdivision to twin fragmentation. The twin fragmentation is more effective in grain refinement [30]. Therefore, finer grain size is achieved in metals with lower SFE.

Fig. 3 shows the engineering stress-strain curves of $\mathrm{Cu}-20 \mathrm{Zn}, \mathrm{Cu}-20 \mathrm{Zn}-1.2 \mathrm{Si}$ and $\mathrm{Cu}-\mathrm{Zn}-1.9 \mathrm{Si}$ alloys after a thickness reduction of $90 \%$. A significant improvement in ultimate tensile strength (UTS) from $675 \mathrm{MPa}$ to $1002 \mathrm{MPa}$, and an improvement in uniform elongation (UE) and total elongation from $3.8 \%, 8.5 \%$ to $5.4 \%, 9.6 \%$ when the SFE decreases from 18 to $6 \mathrm{~mJ} / \mathrm{m}^{2}$ for $\mathrm{Cu}-20 \mathrm{Zn}$ alloy and $\mathrm{Cu}-20 \mathrm{Zn}-1.9 \mathrm{Si}$ alloy, respectively. The large enhancement in UTS with decreasing SFE derives from fine grain and high densities of dislocations and deformation twins, as indicated in previous experiments [16]. The solid solution of atoms plays a role in improving the strength. However, its influence is negligible compared with other strengthening mechanisms [7]. The inset shows curves of normalized hardening rate-true strain. The work hardening rate $\theta$ can be defined by Eq. (4) [31]:

$$
\theta=\frac{1}{\sigma}(\partial \sigma / \partial \varepsilon)_{\dot{\varepsilon}}
$$

where $\sigma$ is the true stress, $\varepsilon$ is the true strain and $\dot{\varepsilon}$ is the strain rate applied. It can be seen that the work hardening rate increases with decreasing SFE. The work 
hardening rate is closely related to the evolution of dislocation density in plastic deformation [32]. The higher work hardening rate in $\mathrm{Cu}-20 \mathrm{Zn}-1.9 \mathrm{Si}$ alloy is attributed to the high dislocation accumulation capacity caused by deformation twins and suppression of dynamic recovery.

\subsection{Annealing behavior of brasses}

Fig. 4 illustrates the hardness evolution of $\mathrm{Cu}-20 \mathrm{Zn}$ and $\mathrm{Cu}-20 \mathrm{Zn}-1.9 \mathrm{Si}$ alloys annealing at different temperatures for $1 \mathrm{~h}$. Three stages can be seen in Fig. 4. During stage 1, a slight decrease in hardness was detected in $\mathrm{Cu}-20 \mathrm{Zn}$ alloy when the annealing temperature is below $240{ }^{\circ} \mathrm{C}$. It indicates that recovery dominants these processes. However, $\mathrm{Cu}-20 \mathrm{Zn}-1.9 \mathrm{Si}$ alloy exhibits annealing hardening phenomenon at stage 1. An apparent increase in hardness was observed and maximum hardness was achieved at $260{ }^{\circ} \mathrm{C}$. The annealing hardening phenomenon can be attributed to the addition of $\mathrm{Si}$, leading to solute segregation to dislocation which is analogous to the formation of Cottrel atmospheres in interstitial solid solution during recovery [33]. During stage 2, a dramatic decrease in hardness was observed in $\mathrm{Cu}-20 \mathrm{Zn}$ and $\mathrm{Cu}-20 \mathrm{Zn}-1.9 \mathrm{Si}$ alloys when annealing temperatures are beyond $240{ }^{\circ} \mathrm{C}$ and $280{ }^{\circ} \mathrm{C}$, respectively. This must be closely related to the beginning of recrystallization. The higher temperature for the beginning of recrystallization implies that the thermal stability of $\mathrm{Cu}-20 \mathrm{Zn}-1.9 \mathrm{Si}$ alloy is relatively better than that of $\mathrm{Cu}-20 \mathrm{Zn}$ alloy. The introduction of $\mathrm{Si}$ results in an interaction between dislocations and solute atoms, which reduces dislocation mobility and the grain boundaries migration during recovery. Furthermore, a decrease in SFE hinders dislocation movement [16,34]. Therefore, thermal stability is enhanced during annealing. In the final stage 3 , the hardness in $\mathrm{Cu}-20 \mathrm{Zn}$ alloy decreases very slowly due to the conventional grain growth after recrystallization. While the hardness in $\mathrm{Cu}-20 \mathrm{Zn}-1.9 \mathrm{Si}$ alloy scarcely change. It indicates that the grain growth is inhibited in $\mathrm{Cu}-20 \mathrm{Zn}-1.9 \mathrm{Si}$ alloy. It is well known that grain growth involves the migration of grain boundaries [35]. Addition of Si pins grain boundaries, which would impede further grain growth after 
recrystallization.

Fig. 5 shows unique grain color map of $\mathrm{Cu}-20 \mathrm{Zn}$ and $\mathrm{Cu}-20 \mathrm{Zn}-1.9 \mathrm{Si}$ alloys after annealing at $340{ }^{\circ} \mathrm{C}$ and $360{ }^{\circ} \mathrm{C}$, respectively. Grain size distributions (based on diameter) of these two alloys are also shown in Fig. 5. Every color stands for a unique grain with a misorientation larger than $15^{\circ}$. Most grains in $\mathrm{Cu}-20 \mathrm{Zn}$ alloy appear equiaxed with its size in the range of $1 \mu \mathrm{m}$ to $5 \mu \mathrm{m}$. Meanwhile, abnormal grain growth (secondary recrystallization) has started to produce an area fraction $(\sim 5 \%)$ of coarser $(5.5-8.5 \mu \mathrm{m})$ grains, as shown in Fig. 5a, b. This is consistent with a slight decrease in hardness at stage 3 in Fig. 4. The equiaxed grains are distributed homogeneously in $\mathrm{Cu}-20 \mathrm{Zn}-1.9 \mathrm{Si}$ alloy and there is no abnormal grain growth. The average grain size $\bar{d}$ in $\mathrm{Cu}-20 \mathrm{Zn}-1.9 \mathrm{Si}$ alloy $(1.4 \mu \mathrm{m})$ is finer than that in $\mathrm{Cu}-20 \mathrm{Zn}$ alloy $(2.9 \mu \mathrm{m})$.

Fig. 6 presents the distributions of the misorientation angle of $\mathrm{Cu}-20 \mathrm{Zn}$ and $\mathrm{Cu}-20 \mathrm{Zn}-1.9 \mathrm{Si}$ alloys after annealing at $340{ }^{\circ} \mathrm{C}$ and $360{ }^{\circ} \mathrm{C}$, respectively. The misorientation distributions are characterized by a sharp peak near $60^{\circ}$, which are attributed to the significant fraction of $\Sigma 3$ twin boundaries. The $\Sigma 3$ twin boundaries fractions in $\mathrm{Cu}-20 \mathrm{Zn}$ alloy and $\mathrm{Cu}-20 \mathrm{Zn}-1.9 \mathrm{Si}$ alloy are $24.4 \%$ and $36.2 \%$, respectively. Annealing twins can be formed during recrystallization driven by minimizing the total excess energies of boundaries separating newly formed grains, and stacking faults would serve as nuclei for annealing twins [36]. As shown in Fig. 7, the annealing twins originated at the stacking faults (marked by circles) and extended into the dislocation-free recrystallized grain. Therefore, profuse annealing twins were introduced into the $\mathrm{Cu}-20 \mathrm{Zn}-1.9 \mathrm{Si}$ alloy by decreasing the SFE. As expected, a large number of annealing twins would increase the proportions of $\Sigma 3$ twin boundaries.

A lower SFE results in a higher defect density, leading to an enhancement in driving force for recrystallization. Consequently, there are more nucleation sites, resulting in finer size of SRX grains [37]. Furthermore, the high formation rate of annealing twins in lower SFE metals may also play crucial roles in hindering grain growth during recrystallization [35]. Compared with conventional HAGBs, $\Sigma 3$ twin boundaries are more stable due to the excess energy of $\Sigma 3$ twin boundaries is one 
order of magnitude lower than that of HAGBs $[35,36]$. These $\Sigma 3$ twin boundaries can impede grain boundaries migration and then delay the growth of newly generated grains [35]. Accordingly, abnormal grain growth is inhibited and finer grain size is achieved in $\mathrm{Cu}-20 \mathrm{Zn}-1.9 \mathrm{Si}$ with lower SFE.

Fig. 8 shows distributions of the main texture components of $\mathrm{Cu}-20 \mathrm{Zn}$ and $\mathrm{Cu}-20 \mathrm{Zn}-1.9 \mathrm{Si}$ alloys annealed at $300{ }^{\circ} \mathrm{C}$ and $340{ }^{\circ} \mathrm{C}$, respectively. $\Sigma 3$ twin boundaries are designated by thin gray lines. For comparison, several ideal rolling and recrystallization textures in fcc metals are listed in Table 2. Both $\mathrm{Cu}-20 \mathrm{Zn}$ and $\mathrm{Cu}-20 \mathrm{Zn}-1.9 \mathrm{Si}$ alloys mainly comprised $\{236\}\langle 385\rangle$ Brass- $\mathrm{R}$ and $(55 ; 30 ; 0)$. The fractions of rolling textures were small. The fractions of the $\{236\}\langle 385\rangle$ Brass $-\mathrm{R}$ and $(55 ; 30 ; 0)$ in $\mathrm{Cu}-20 \mathrm{Zn}-1.9 \mathrm{Si}$ alloy are $22.2 \%$ and $15.1 \%$, respectively. However, lower fractions of these two textures in $\mathrm{Cu}-20 \mathrm{Zn}$ alloy are $12.8 \%$ and $8.5 \%$, respectively.

The recrystallized texture is dependent on the character of the deformed microstructures. The formation of Brass texture has been attributed to the suppression of dislocation movement. Brass texture would be the dominant texture in the deformed microstructures with a decrease in SFE [38-40]. Brass-R texture, the major component of the recrystallization texture of fcc metals with low SFE, is most favorable to growth into the microstructures with the brass type rolling textures [41]. Moreover, a decrease in SFE would facilitate the formation of deformation twins. Due to the deformation twins in the deformed microstructures, the newly formed deformation twins possess the $\{236\}\langle 385\rangle$ Brass-R orientation, and this can grow very quickly during annealing process.[42]. Owing to $(55 ; 30 ; 0)$ orientation is relatively close to Brass. It is possible that the $(55 ; 30 ; 0)$ grains derived from orientation spread of the Brass component[39]. Therefore, it is reasonable to expect that higher fractions of the $\{236\}\langle 385\rangle$ Brass-R and $(55 ; 30 ; 0)$ obtained in $\mathrm{Cu}-20 \mathrm{Zn}-1.9 \mathrm{Si}$ alloy.

Fig. 9 shows the effect of SFE on the strength-ductility relationship. The strength-ductility trend of $\mathrm{Cu}-20 \mathrm{Zn}-1.9 \mathrm{Si}$ alloy with lower SFE is shifted upwards compared to the $\mathrm{Cu}-20 \mathrm{Zn}$ and $\mathrm{Cu}-20 \mathrm{Zn}-1.2 \mathrm{Si}$ alloys. With the same uniform 
elongation, the UTS of $\mathrm{Cu}-20 \mathrm{Zn}-1.9 \mathrm{Si}$ alloy is higher than that of $\mathrm{Cu}-20 \mathrm{Zn}$ and $\mathrm{Cu}-20 \mathrm{Zn}-1.2 \mathrm{Si}$ alloys by $100-300 \mathrm{MPa}$. Or, with the same UTS, Cu-20Zn-1.9Si alloy exhibits a $2-10 \%$ higher $\mathrm{UE}$ than $\mathrm{Cu}-20 \mathrm{Zn}$ and $\mathrm{Cu}-20 \mathrm{Zn}-1.2 \mathrm{Si}$ alloys. Clearly, compared with $\mathrm{Cu}-20 \mathrm{Zn}$ and $\mathrm{Cu}-20 \mathrm{Zn}-1.2 \mathrm{Si}$ alloys, the $\mathrm{Cu}-20 \mathrm{Zn}-1.9 \mathrm{Si}$ alloy exhibits a superior strength-ductility combination after annealing.

The superior strength-ductility combination of $\mathrm{Cu}-20 \mathrm{Zn}-1.9 \mathrm{Si}$ alloy may be attributed to several factors. In terms of strength, the high strength with decreasing SFE may originate from two factors. First, the fine grains after annealing impart high strength, as expected from the Hall-Petch relationship. Second, dislocation movement is impeded due to the deformation twins and abundant annealing twins with a decrease in SFE and thus the strength is improved. [7,16,43]. The enhancement in ductility can be attributed to the following three factors. First, it is well known that the UE is determined by the work hardening rate [16]. With a decrease in SFE, cross slip is significantly blocked as a dynamic recovery mechanism and thus the work hardening rate is improved [16]. Second, with decreasing SFE, the formation of high density of annealing twins may in favor of accumulating more dislocations to improve the work hardening ability. Moreover, stacking fault may interact effectively with slipping dislocations, leading to an increase in work hardening ability. Therefore, the ductility is enhanced [44-46]. Third, the easy formation of deformation twins during tensile test in the recrystallized grains not only provides ample room for dislocation storage but also improves the work hardening rate, thereby to further enhance the ductility $[47,48]$.

\section{Conclusions}

The effect of stacking fault energy (SFE) on mechanical properties and annealing behavior of brasses was studied and can be summarized as follows:

(1) Investigations by $\mathrm{X}$-ray diffraction indicate that a decrease in SFE leads to both a decrease in the grain size and an increase in the densities of dislocations and deformation twins. 
(2) A significant increase in the strength has been observed by lowing SFE. This is due to the formation of fine grains and high densities of dislocations and deformation twins.

(3) Thermal stability is enhanced due to the reductions of dislocation mobility and grain boundaries migration during annealing by a decrease in SFE and addition of Si.

(4) High fractions of the $\{236\}\langle 385\rangle$ Brass- $\mathrm{R}$ and $(55 ; 30 ; 0)$ in $\mathrm{Cu}-20 \mathrm{Zn}-1.9 \mathrm{Si}$ alloy with lower SFE may result from the substantial Brass texture in deformed microstructures.

(5) The superior strength-ductility combination in $\mathrm{Cu}-20 \mathrm{Zn}-1.9 \mathrm{Si}$ alloy with lower SFE originates from the fine grains, deformation twins and abundant annealing twins.

\section{Acknowledgements}

The authors gratefully acknowledge support from the National Science Foundation of China (NO. 51174234). 


\section{References}

[1] Meyers MA, Vöhringer O, Lubarda VA. The onset of twinning in metals: a constitutive description. Acta Mater 2001;49:4025-4039.

[2] Mahajan S, Pande CS, Lman MA, Rath BB. Formation of annealing twins in f.c.c. crystals. Acta Mater 1997;45:2633-2638.

[3] Zhu YT, Huang JY, Gubicza J, Ungar T, Wang YM, Ma E, Valiev. Nanostructures in Ti processed by severe plastic deformation. J Mater Res 2003;18:1908-1917.

[4] Tao NR, Wang ZB, Tong WP, Sui ML, Lu J, Lu K. An investigation of surface nanocrystallization mechanism in $\mathrm{Fe}$ induced by surface mechanical attrition treatment. Acta Mater 2002;50:4603-4616.

[5] Dobatkin SV, Bastarache EN, Sakai G, Fujita T, Horita Z, Langdon TG. Grain refinement and superplastic flow in an aluminum alloy processed by high-pressure torsion. Mater Sci Eng A 2005;408:141-146.

[6] Kumar NK, Roy B, Das J. Effect of twin spacing, dislocation density and crystallite sizeon the strength of nanostructured a-brass. J Alloys Compd 2015;618:139-145.

[7] Qu S, An XH, Yang HJ, Huang CX, Yang G. Zang QS, Wang ZG, Wu SD, Zhang ZF. Microstructural evolution and mechanical properties of $\mathrm{Cu}-\mathrm{Al}$ alloys subjected to equal channel angular pressing. Acta Mater 2009;57:1586-1601.

[8] Hughes DA, Hansen N. High angle boundaries formed by grain subdivision mechanisms. Acta Mater 1997;45:3871-3886.

[9] Tao NR, Lu K. Nanoscale structural refinement via deformation twinning in face-centered cubic metals. Scr Mater 2009;60:1039-1043. 
[10] Wang YM, Chen MW, Zhou FH, Ma E. High tensile ductility in a nanostructured metal. Nature 2002;419:912-914.

[11] Wu D, Chen RS, Han EH. Excellent room-temperature ductility and formability of rolled Mg-Gd-Zn alloy sheets. J Alloy Compd 2011;509:2856-2863.

[12] Huang XX, Hansen N, Tsuji N. Hardening by Annealing and Softening by Deformation in Nanostructured Metals. Science 2006;312:249-251.

[13] Fatemi-Varzaneh SM, Zarei-Hanzaki A, Haghshenas M. The room temperature mechanical properties of hot-rolled AZ31 magnesium alloy. J Alloy Compd 2009;475:126-130.

[14] Zhao YH, Bingert JF, Liao XZ, Cui BZ, Han K, Sergueeva AV et al. Simultaneously Increasing the Ductility and Strength of Ultra-Fine-Grained Pure Copper. Adv Mater 2006;18:2949-2953.

[15] Han WZ, Zhang ZF, Wu SD, Li SX. Combined effects of crystallographic orientation, stacking fault energy and grain size on deformation twinning in FCC crystals. Philos Mag 2008;88:3011-3029.

[16] An XH, Wu SD, Zhang ZF, Figueiredo RB, Gao N, Langdon TG. Enhanced strength-ductility synergy in nanostructured $\mathrm{Cu}$ and $\mathrm{Cu}-\mathrm{Al}$ alloys processed by high-pressure torsion and subsequent annealing. Scr Mater 2012;66:227-230.

[17] Sarma VS, Sivaprasad K, Sturm D, Heilmaier M. Microstructure and mechanical properties of ultra fine grained $\mathrm{Cu}-\mathrm{Zn}$ and $\mathrm{Cu}-\mathrm{Al}$ alloys produced by cryorolling and annealing. Mater Sci Eng A 2008;489:253-258.

[18] Oishi K, Sasaki I, Otani J. Effect of silicon addition on grain refinement of copper 
alloys. Mater Lett 2003;57:2280-2286.

[19] Denanot MF, Villain JP. The Stacking Fault Energy in Cu-Al-Zn Alloys. Phys Status Solid (a) 1971;8:125-127

[20] Zhang Y, Tao NR, Lu K. Mechanical properties and rolling behaviors of nano-grained copper with embedded nano-twin bundles. Acta Mater 2008;56: $2429-2440$

[21] Wagner CNJ. Stacking faults by low-temperature cold work in copper and alpha brass. Acta Metall 1957;5:427-434.

[22] Cohen JB, Wagner CNJ. Determination of Twin Fault Probabilities from the Diffraction Patterns of fcc Metals and Alloys. J Appl Phys 1962;33:2073-2077.

[23] Ungár T, Ott S, Sanders PG, Borbély A, Weertman JR. Dislocations, grain size and planar faults in nanostructured copper determined by high resolution X-ray diffraction and a new procedure of peak profile analysis. Acta Mater 1998;46:3693-3699.

[24] Zhao TH, Zhu YT, Liao XZ, Horita Z, Langdon TG. Tailoring stacking fault energy for high ductility and high strength in ultrafine grained $\mathrm{Cu}$ and its alloy. Appl Phys Lett 2006;89:121906-1

[25] Wu XX, Wen CE, Gong YL, Ren SY, Tao JM, Chen LP, Long Y, Zhu XK. Effect of stacking fault energy and strain rate on the mechanical properties of $\mathrm{Cu}$ and $\mathrm{Cu}$ alloys. J Alloy Compd 2013;573:1-5.

[26] Rohatgi A, Vecchio KS, Gray III GT. The Influence of Stacking Fault Energy on the Mechanical Behavior of $\mathrm{Cu}$ and $\mathrm{Cu}-\mathrm{Al}$ Alloys: Deformation Twinning,Work 
Hardening, and Dynamic Recovery. Metall Mater Trans A 2001;32:135-145.

[27] Cubicza J, Chinh NQ, Labar LJ, Hegedus Z, Langdon TG. Principles of self-annealing in silver processed by equal-channel angular pressing: The significance of a very low stacking fault energy. Mater Sci Eng A 2011;527:752-760.

[28] Christian JW, Mahajan S. Deformation twinning. Prog Mater Sci 1995;39:1-157.

[29] Rohatgi A, Vecchio KS, Gray III GT. A metallographic and quantitative analysis of the influence of stacking fault energy on shock-hardening in $\mathrm{Cu}$ and $\mathrm{Cu}-\mathrm{Al}$ alloys. Acta Mater 2001;49:427-438.

[30] Gong YL, Wen CE, Wu XX, Ren SY, Cheng LP, Zhu XK. The influence of strain rate, deformation temperature and stacking fault energy on the mechanical properties of Cu alloys. Mater Sci Eng A 2013;583:199-204.

[31] Ye YX, Yang XY, Liu CZ, Shen YZ, Zhang XK, Sakai T. Enhancement of strength and ductility of $\mathrm{Cu}-\mathrm{Sn}-\mathrm{Zn}$ alloy by iron addition. Mater Sci Eng A $2014 ; 612: 246-252$.

[32] Bahmanpour H, Kauffmann A, Khoshkhoo MS, Youssef KM, Mula S, Freudenberger J, Eckert J, Scattergood RO, Koch CC. Effect of stacking fault energy on deformation behavior of cryo-rolled copper and copper alloys. Mater Sci Eng A 2011;529:230-236.

[33] Nestorovic S, Markovic D. Influence of alloying on the annealing hardening effect in sintered copper alloys. Mater Trans 1999;40:222-224.

[34] Zhang HW, Lu K, Pippan R, Huang X, Hansen N. Enhancement of strength and 
stability of nanostructured $\mathrm{Ni}$ by small amounts of solutes. Scr Mater 2011;65:481-484.

[35] Humphreys FJ, Hatherly M. Recrystallization and Related Annealing Phenomena. Second ed. 2004 Elsevier, Oxford.

[36] Xue P, Xiao BL, Ma ZY. Enhanced strength and ductility of friction stir processed $\mathrm{Cu}-\mathrm{Al}$ alloys with abundant twin boundaries. Scr Mater 2013;68:751-754.

[37] An XH, Qu S, Wu SD, Zhang ZF. Effects of stacking fault energy on the thermal stability and mechanical properties of nanostructured $\mathrm{Cu}-\mathrm{Al}$ alloys during thermal annealing. J Mater Res 2011;26:407-415.

[38] Konkova T, Mironov S, Korznikov A, Myshlyaev MM, Semiatin SL. Grain structure evolution during cryogenic rolling of alpha brass. J Alloy Compd 2015;629:140-147.

[39] Konkova T, Mironov S, Korznikov A, Semiatin SL. Annealing behavior of cryogenically-rolled copper. Mater Sci Eng A;2013;585:178-189.

[40] Smallman RE, Green D. The dependence of rolling texture on stacking fault energy. Acta Metall 1964;12:145-154.

[41] Sztwiertnia K. Recrystallization textures and the concept of oriented growth revisited. Mater Lett 2014;123:41-43.

[42] Chowdhury SG, Das S, Ravikumar B, De PK. Twinning-Induced Sluggish Evolution of Texture during Recrystallization in AISI 316L Stainless Steel After Cold Rolling. Metall Mater Trans A 2006;37:2349-2359.

[43] Pande CS, Rath BB, Iman MA. Effect of annealing twins on Hall-Petch relation in 
polycrystalline materials. Mater Sci Eng A 2014;367:171-175.

[44] Lu K, Lu L, Suresh S. Strengthening Materials by Engineering Coherent Internal Boundaries at the Nanoscale. Science 2009;324:349-352.

[45] Chen XH, Lu L, Lu K. Grain size dependence of tensile properties in ultrafine-grained $\mathrm{Cu}$ with nanoscale twins. Scr Mater 2011;64:311-314.

[46] Zhao YH, Liao XZ, Horita Z, Langdon TG, Zhu YT. Determining the optimal stacking fault energy for achieving high ductility in ultrafine-grained $\mathrm{Cu}-\mathrm{Zn}$ alloys. Mater Sci Eng A 2008;493:123-129.

[47] Bouaziz O, Allain S, Scott C. Effect of grain and twin boundaries on the hardening mechanisms of twinning-induced plasticity steels. Scr Mater 2008;58:484-487.

[48] Wang ZW, Wang YB, Liao XZ, Zhao YH, Lavernia EJ, Zhu YT, Horita Z, Langdon TG. Influence of stacking fault energy on deformation mechanism and dislocation storage capacity in ultrafine-grained materials. Scr Mater 2009;60:52-55. 


\section{Figures captions}

Fig. 1. Three-dimensional EBSD micrographs of the $\mathrm{Cu}-20 \mathrm{Zn}$ and $\mathrm{Cu}-20 \mathrm{Zn}-1.9 \mathrm{Si}$ alloys at a thickness reduction of 30\%: (a) Cu-20Zn alloy; (b) $\mathrm{Cu}-20 \mathrm{Zn}-1.9 \mathrm{Si}$ alloy.

Fig. 2. TEM micrographs of $\mathrm{Cu}-20 \mathrm{Zn}$ and $\mathrm{Cu}-20 \mathrm{Zn}-1.9 \mathrm{Si}$ alloys at a thickness reduction of 90\%; $\mathrm{Cu}-20 \mathrm{Zn}$ alloy: (a) rolling plane (b) longitudinal plane Cu-20Zn-1.9Si alloy: (c) rolling plane (d) longitudinal plane.

Fig. 3. Engineering stress-strain curves of the $\mathrm{Cu}-20 \mathrm{Zn}, \mathrm{Cu}-20 \mathrm{Zn}-1.2 \mathrm{Si}$ and $\mathrm{Cu}-20 \mathrm{Zn}-1.9 \mathrm{Si}$ alloys at a thickness reduction of $90 \%$. The inset shows curves of normalized hardening rate-true strain.

Fig. 4. Hardness data of $\mathrm{Cu}-20 \mathrm{Zn}$ and $\mathrm{Cu}-20 \mathrm{Zn}-1.9 \mathrm{Si}$ alloys annealed at different temperatures for $1 \mathrm{~h}$.

Fig. 5. (a) Unique grain color map and (b) Grain size distributions of Cu-20Zn alloy annealed at $340{ }^{\circ} \mathrm{C}$. (c) Unique grain color map and (d) Grain size distributions of $\mathrm{Cu}-20 \mathrm{Zn}-1.9 \mathrm{Si}$ alloy annealed at $360{ }^{\circ} \mathrm{C}$.

Fig. 6. Misorientation angle distributions of (a) $\mathrm{Cu}-20 \mathrm{Zn}$ alloy after annealing (b) Cu-20Zn -1.9 Si alloy after annealing.

Fig. 7. TEM micrograph of annealing twins originated from stacking faults (marked by circles).

Fig. 8. Distributions of the main texture components within the EBSD maps: (a) $\mathrm{Cu}-20 \mathrm{Zn}$ annealed at $300{ }^{\circ} \mathrm{C}$; (b) $\mathrm{Cu}-20 \mathrm{Zn}-1.9 \mathrm{Si}$ annealed at $340{ }^{\circ} \mathrm{C} .(\Sigma 3$ twin boundaries are designated by thin gray lines) 
Fig. 9. Variation in UTS with UE for $\mathrm{Cu}-20 \mathrm{Zn}, \mathrm{Cu}-20 \mathrm{Zn}-1.2 \mathrm{Si}$ and $\mathrm{Cu}-20 \mathrm{Zn}-1.9 \mathrm{Si}$ alloys under different annealing conditions. 
Fig. 1.

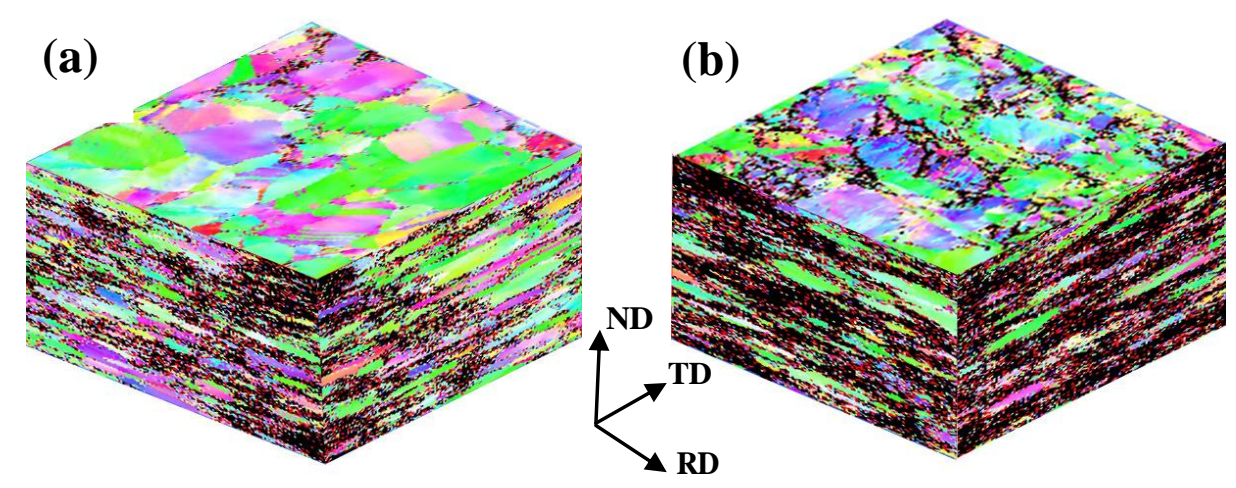


Fig. 2.

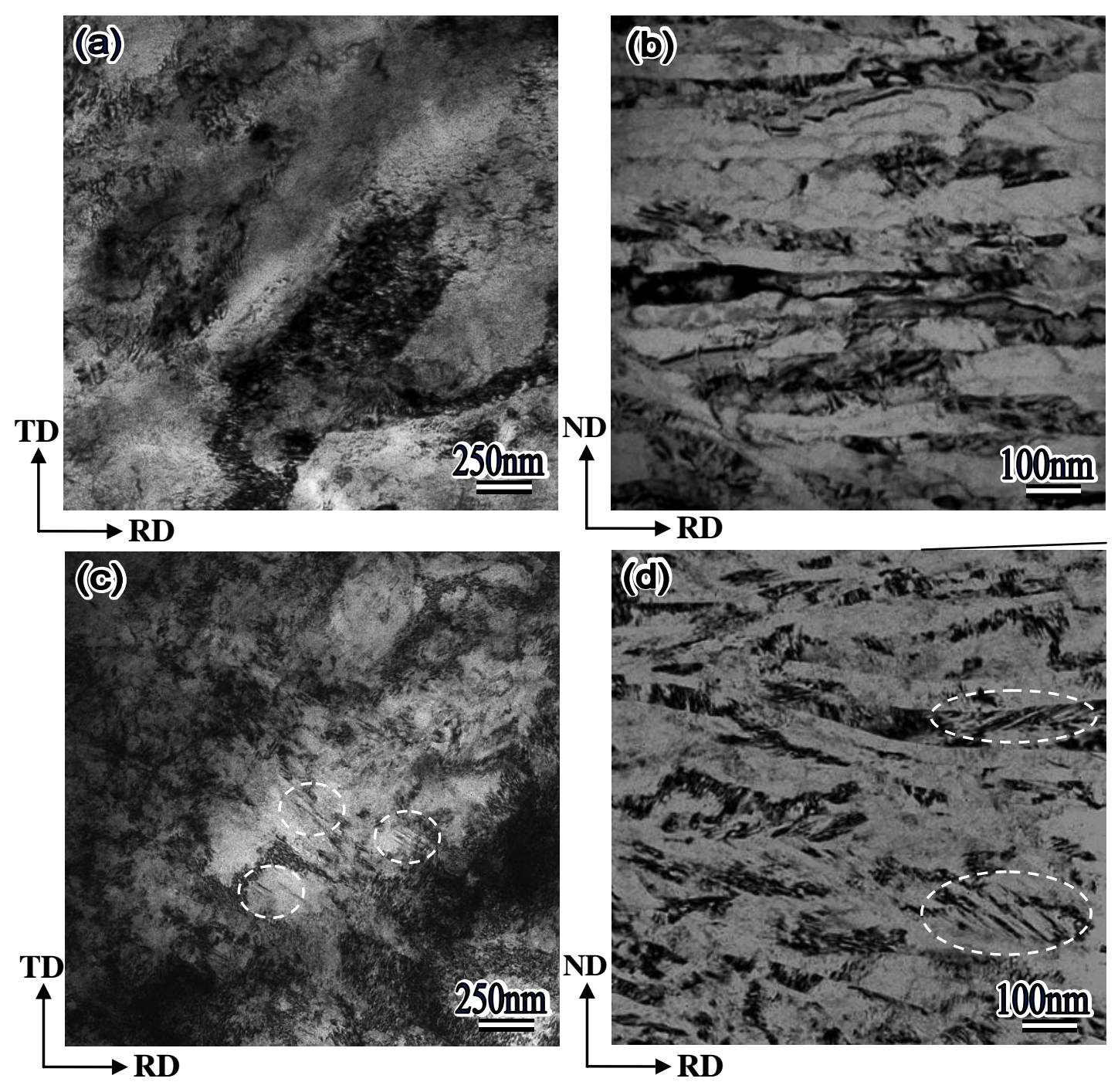


Fig. 3.

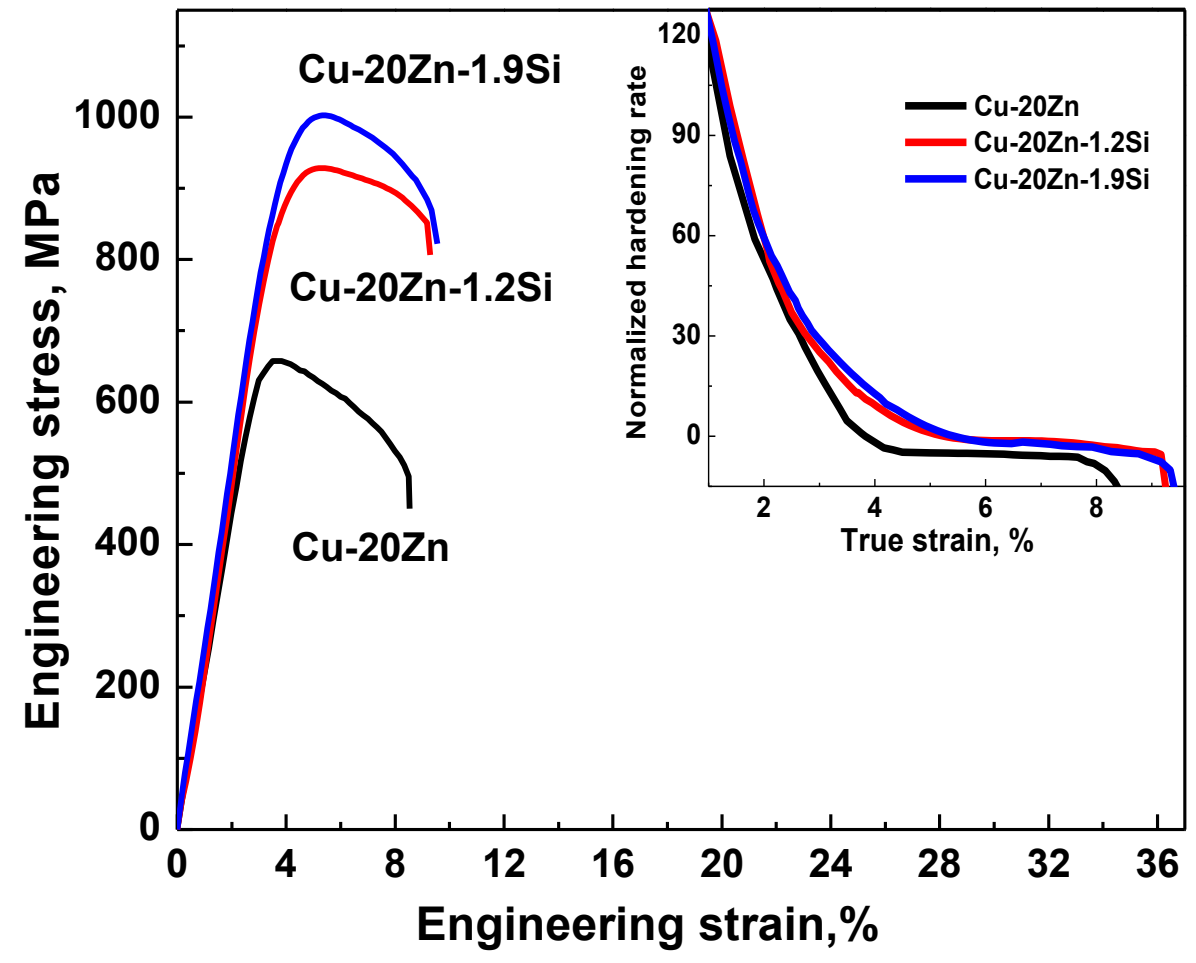


Fig. 4.

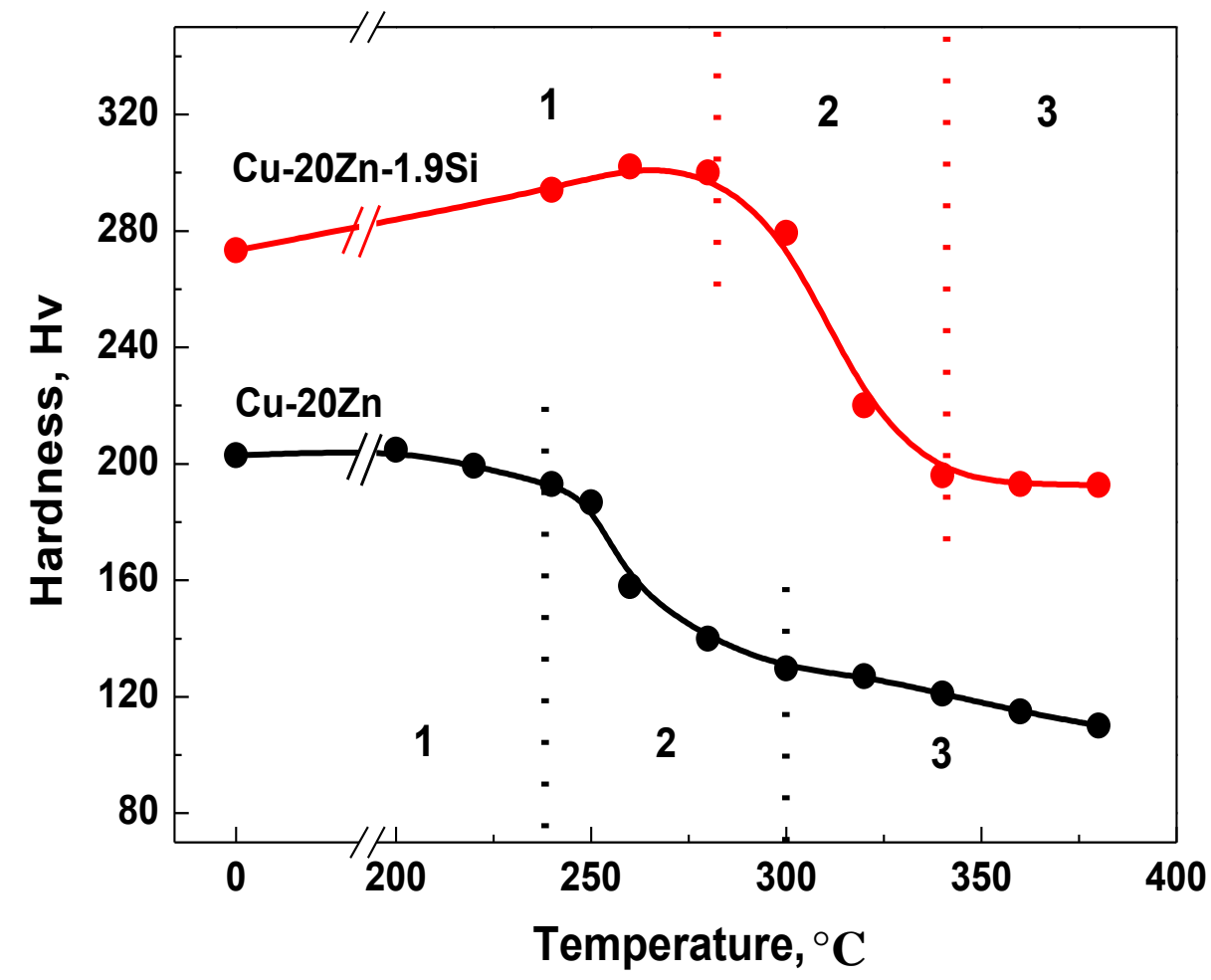


Fig. 5.
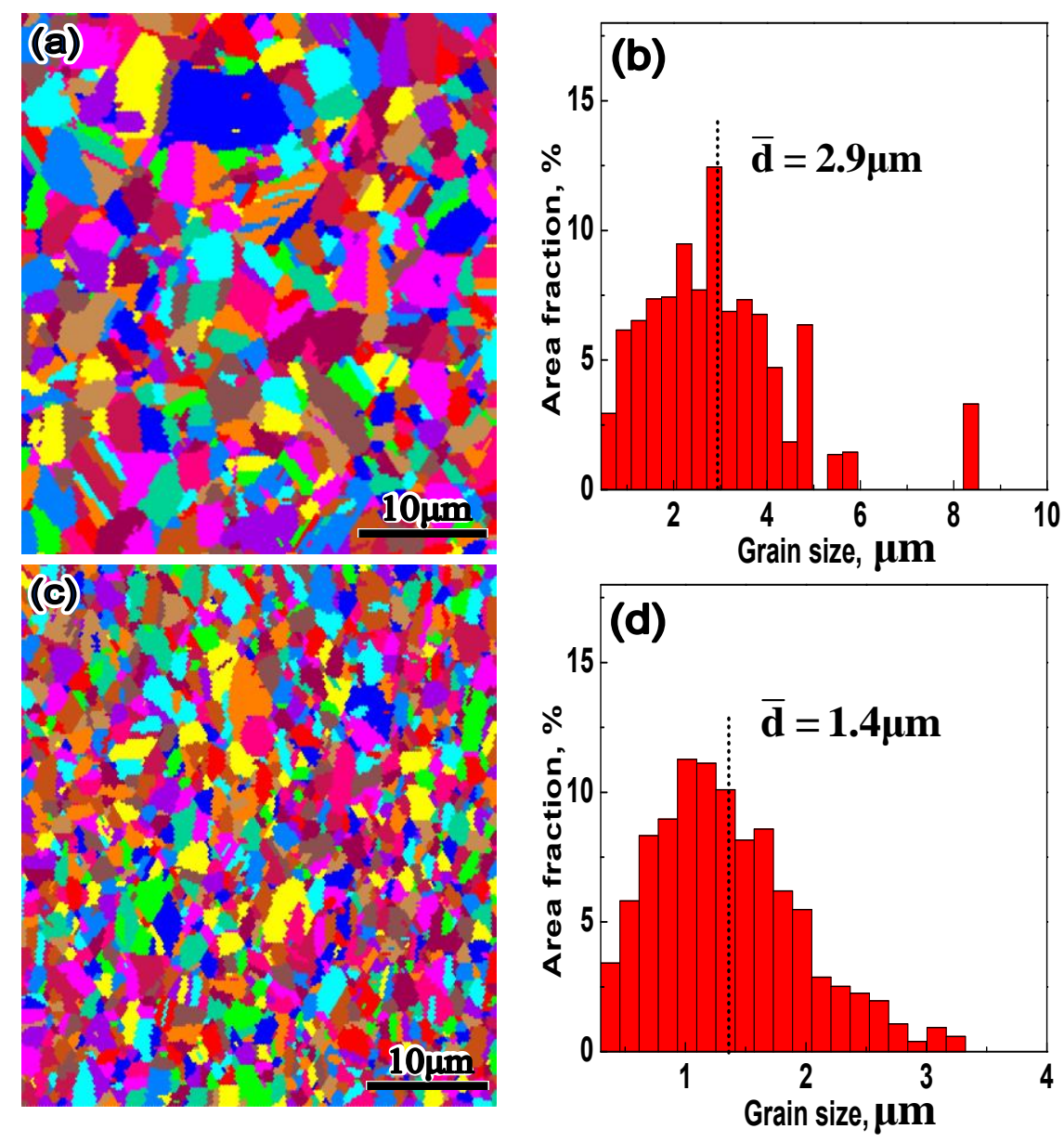
Fig. 6.
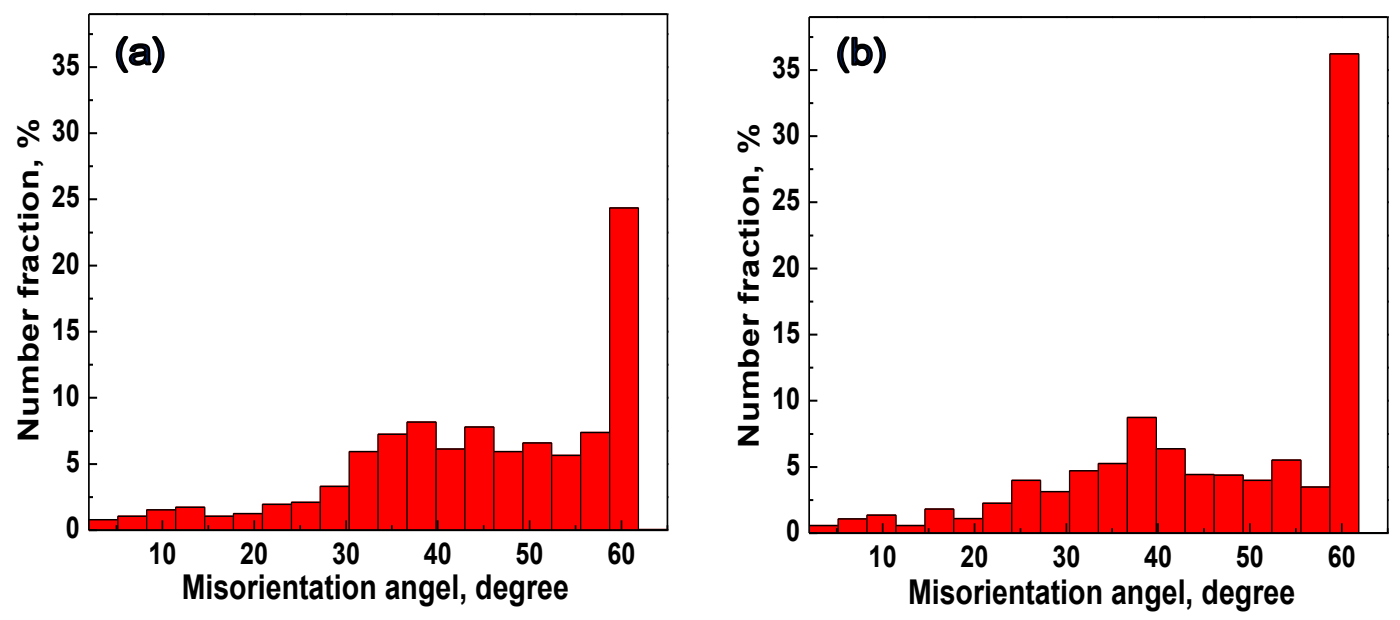
Fig. 7.

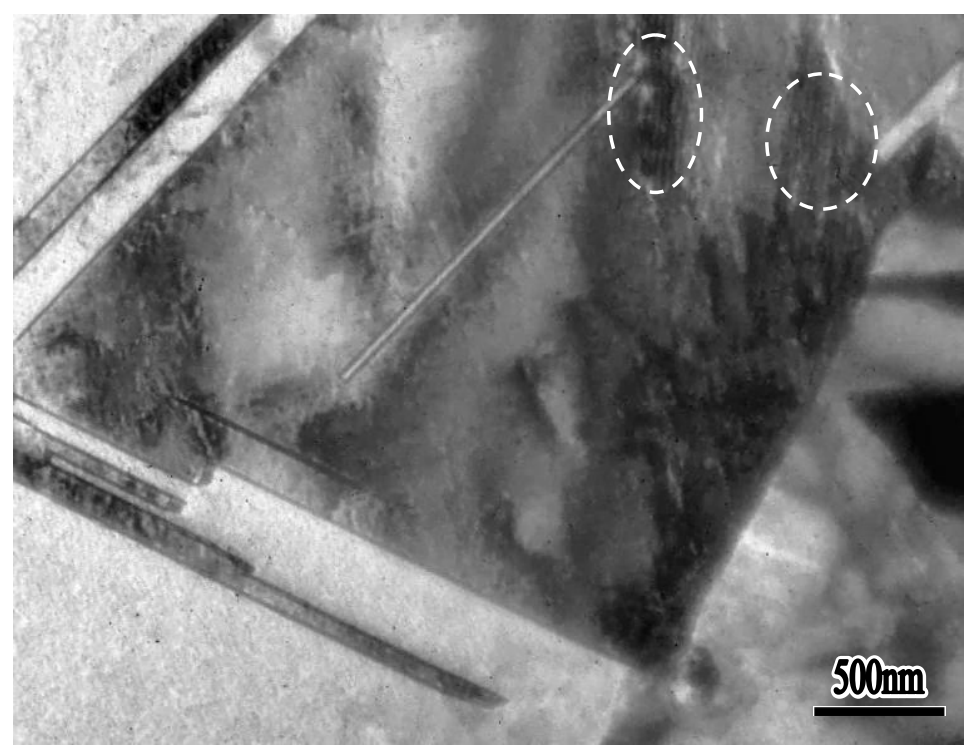


Fig. 8.

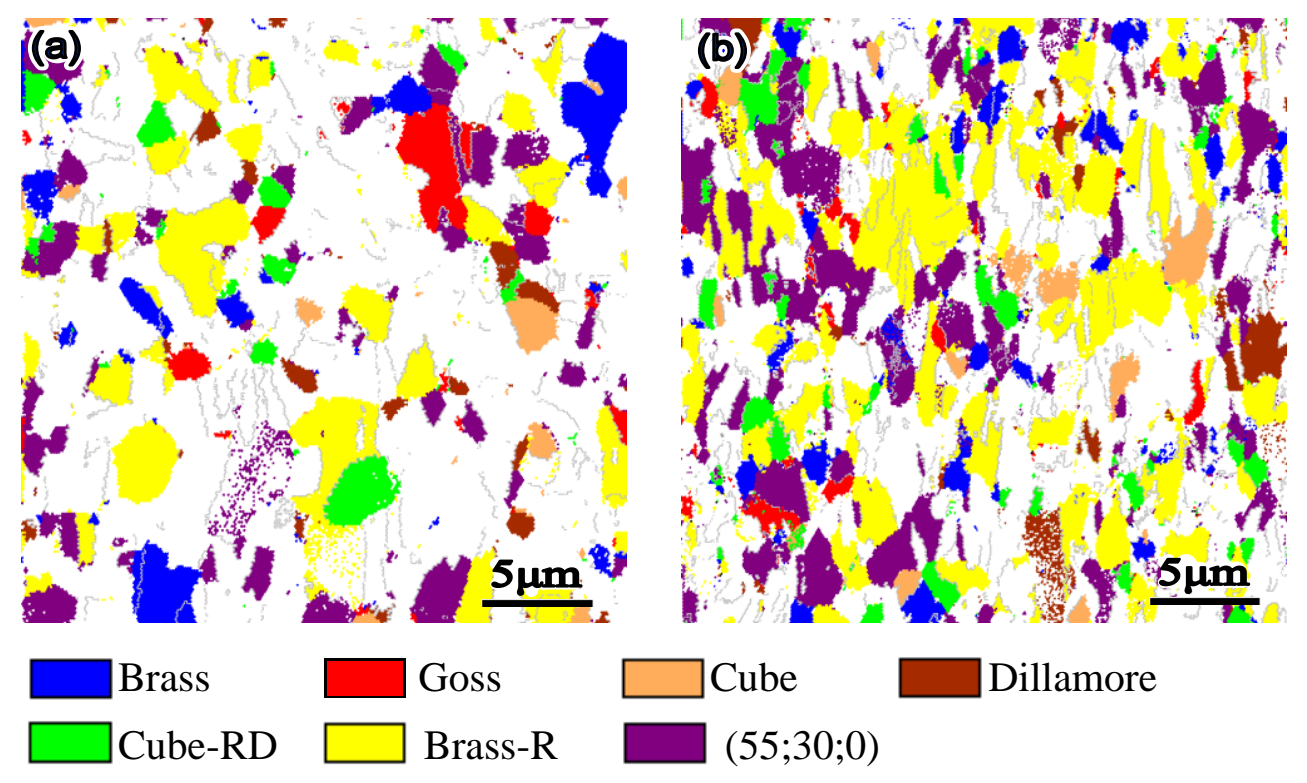


Fig. 9.

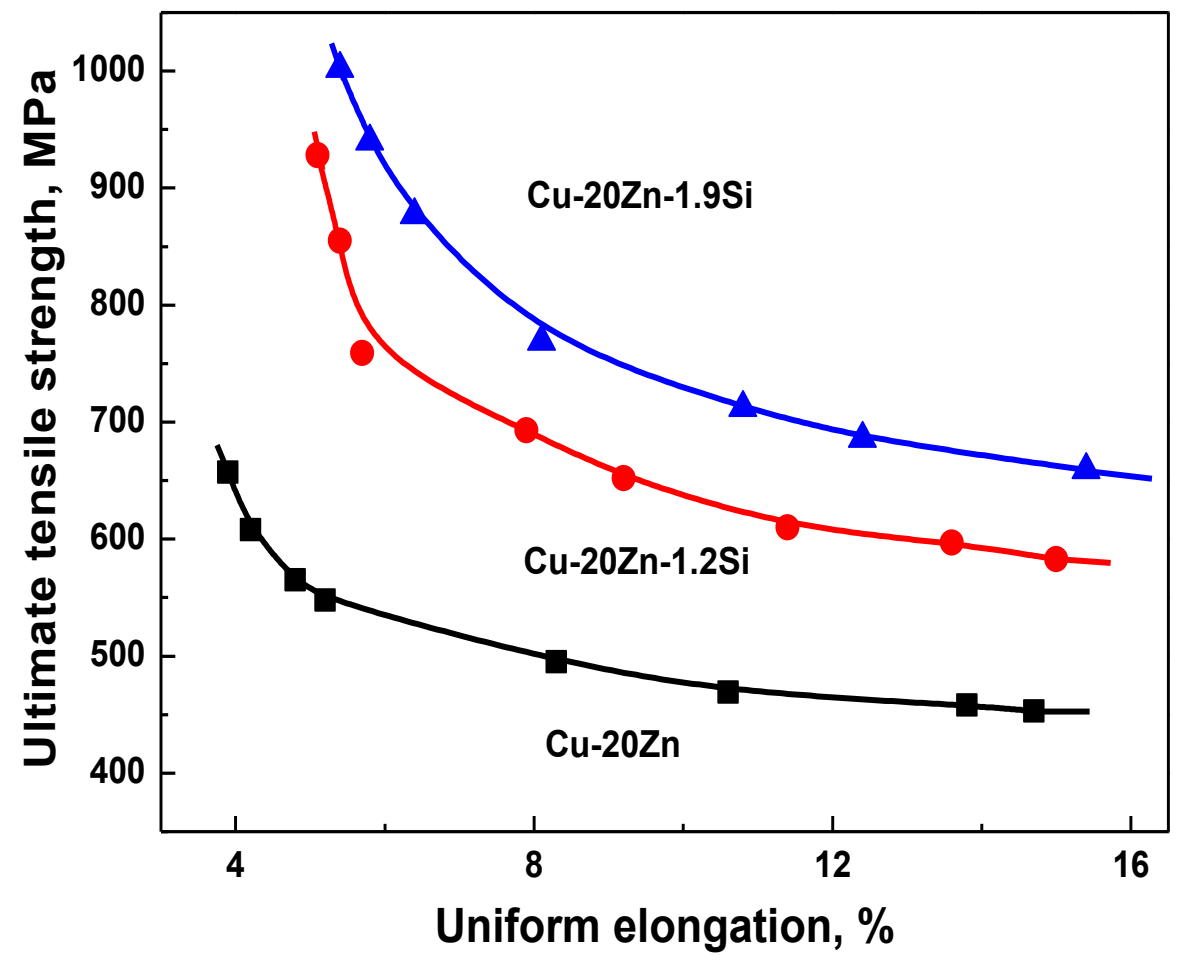


Table 1 Dislocation density $\rho$, twin density $\beta$ and average grain size $\bar{d}$ of brasses

\begin{tabular}{cccc}
\hline & $\mathrm{Cu}-20 \mathrm{Zn}$ & $\mathrm{Cu}-20 \mathrm{Zn}-1.2 \mathrm{Si}$ & $\mathrm{Cu}-20 \mathrm{Zn}-1.9 \mathrm{Si}$ \\
\hline$\gamma, \mathrm{mJ} / \mathrm{m}^{2}$ & 18 & 9 & 6 \\
\hline$\rho, 10^{15} \mathrm{~m}^{-2}$ & 1.6 & 4.55 & 6.1 \\
\hline$\beta, \%$ & 0.05 & 0.14 & 0.26 \\
\hline $\bar{d}, \mathrm{~nm}$ & 103 & 51 & 42 \\
\hline
\end{tabular}

Table 2 Several ideal rolling and recrystallization textures for face-centered cubic metals.

\begin{tabular}{llllll}
\hline orientation & \multicolumn{3}{c}{ Euler angles $(\mathrm{deg})$} & \multicolumn{2}{c}{ Miller indices } \\
\cline { 2 - 6 } Rolling textures & $\varphi_{1}$ & $\phi$ & $\varphi_{2}$ & $\begin{array}{l}\text { Rolling } \\
\text { plane }\end{array}$ & $\begin{array}{l}\text { Rolling } \\
\text { direction }\end{array}$ \\
Brass & 35 & 45 & 0 & $\{011\}$ & $\langle 211\rangle$ \\
Goss & 0 & 45 & 90 & $\{011\}$ & $\langle 100\rangle$ \\
Cube & 0 & 0 & 0 & $\{001\}$ & $\langle 100\rangle$ \\
Dillamore & 90 & 27 & 45 & $\{4 ; 4 ; 11\}$ & $\langle 11 ; 11 ; 8\rangle$ \\
& & & & & \\
Recrystallization & textures & & & & \\
Cube-RD & 0 & 22 & 0 & $\{013\}$ & $\langle 100\rangle$ \\
Brass-R & 80 & 31 & 35 & $\{236\}$ & $\langle 385\rangle$ \\
\hline
\end{tabular}

